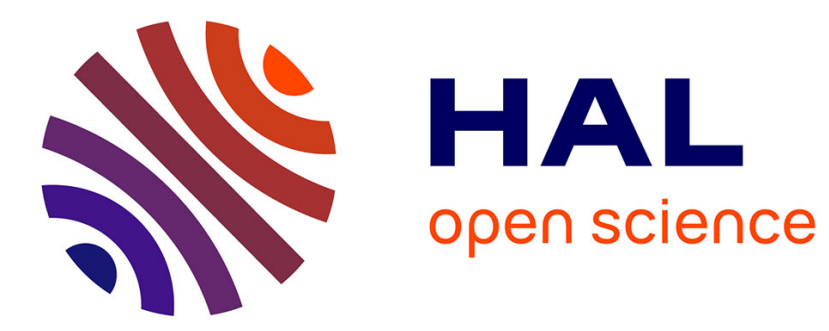

\title{
Creativity from Design and Innovation Perspectives
} Joelle Forest, Denis Choulier, Eric Coatanéa, Mohamed Bakhouya

\section{To cite this version:}

Joelle Forest, Denis Choulier, Eric Coatanéa, Mohamed Bakhouya. Creativity from Design and Innovation Perspectives. Encyclopedia on creativity, invention, innovation and entrepreneurship, Springer, 2800 p, 2013, 10.1007/978-1-4614-3858-8 . halshs-00805520

\section{HAL Id: halshs-00805520 \\ https://shs.hal.science/halshs-00805520}

Submitted on 7 Nov 2014

HAL is a multi-disciplinary open access archive for the deposit and dissemination of scientific research documents, whether they are published or not. The documents may come from teaching and research institutions in France or abroad, or from public or private research centers.
L'archive ouverte pluridisciplinaire HAL, est destinée au dépôt et à la diffusion de documents scientifiques de niveau recherche, publiés ou non, émanant des établissements d'enseignement et de recherche français ou étrangers, des laboratoires publics ou privés. 


\section{Creativity from Design and Innovation Perspectives}

To cite this version:

Joelle Forest, Denis Choulier, Galina Medyna, Eric Coatanéa, Francois Christophe, Mohamed Bakhouya, Creativity from Design and Innovation Perspectives, in E.G. Carayannis (ed.), Encyclopedia on creativity, invention, innovation and entrepreneurship, pp. 403409, Springer : New York.

\section{Introduction:}

The notion of innovation is associated with abundant literature presenting a variety of viewpoints, some complementary and others contradictory. In this literature the concept of innovation is often associated with novelty and the added value provided by new products, processes or services to groups or individuals. This viewpoint is clearly present in the third edition of the Oslo Manual (2005) which defines innovation as "the implementation of a new or significantly improved product (good or service), or process; a new marketing method, or a new organizational method in business practices, workplace organization or external relations." Elsewhere the same reference to novelty is used to describe creativity, "the creative process is seen as the sequence of thoughts and actions that leads to a novel, adaptive production" (Lubart, 2010). This type of ambiguity and confusion in the definitions of the two concepts is often encountered in many related works.

The confusion is further maintained by the fact that research in the fields of creativity and innovation address similar questions. For example the Organisation for Economic Cooperation and Development (OECD) definition of innovation defines three levels of "new": new to the world, new to a nation, and new to the firm. Thus this raises the question of whether a product or process that is new to a particular nation, geographic or political region can be considered innovative in the same manner as a product or process that is new to the world, and therefore obviously innovative (Holbrook and Hughes, 2003). Such a question is also considered to be central in creativity research focusing on the analysis of creative products (MacKinnon, 1978) and on the challenge of comparing two novel ideas to show which one is the most creative (Boden, 1996). Moreover, the ambiguity between the concepts of creativity and innovation is accentuated as they seem to correspond to distinct processes, the first being the starting point of the latter (Amabile et al., 1996).

In an attempt to clarify the notions of creativity and innovation, the design process can be considered as the central process of innovation as claimed by Kline and Rosenberg, "the central process of innovation is not science but design" (Kline, Rosenberg, 1986). Multiple recent studies confirm Kline and Rosenberg's statement by providing pragmatic evidence that design plays a major role in innovation. For instance, a recent survey of Swedish companies shows that firms that use design activities geared toward innovation as a strategic driver are five times more likely to develop new products as compared to firms that do not (Swedish Industrial Design Foundation, 2008; European Commission, 2009). Moreover, these firms increase their chances of developing radical innovation (Irish Center for Design Innovation, 2007; Tether, 2009).

This article aims to explore the relationship between creativity, design, and innovation. To this end, a first part develops a short state of the art review of creativity and the point of view of creativity as a process. Then, design is presented as a process and considered in its creative character. In a third part, the link between creativity and design is made through the notion of 
ingenium. Finally the article introduces a new manner of considering creativity from a design centered perspective.

\section{Creativity as a process:}

Interest in research linked to the field of creativity began to grow in the 1950s. In 1950, Guilford emphasized the scarcity of research on creativity: less than $0.25 \%$ (only 183 among 121,000 abstracts) of the entries in Psychological Abstracts for the preceding 23 years dealt with the subject of creativity (Guilford, 1950). He then went on to underline the social importance of creativity and invited his colleagues to develop research on the topic.

Since then theories on creativity have focused on a variety of aspects. Rhodes was the first, in 1961, to note that there are four fundamental areas of inquiry in creativity research. He called these areas the four P's of creativity,referring to person, product, place and process .

The first one focuses on the characteristics of the creative person which, related research shows, tends to have such characteristics as risk taking, autonomy, humor, open-mindedness, tolerance of ambiguity, curiosity, etc. Researchers have also studied creativity aspects linked to the creative product, "the starting point, indeed the bedrock of all studies of creativity, is an analysis of creative products, a determination of what makes them different from more mundane products" (MacKinnon, 1978:187). The focus on place considers the best circumstances which nurture creativity; these include degrees of autonomy, access to resources, and the nature of gatekeepers. The final $\mathrm{P}$, process, examines the thinking stages occurring when people behave in a creative manner; this aspect has been principally studied in psychology and cognitive science. To consider creativity as a process means adhering to a tradition of thought that diverges from the myth of creativity being a matter of divine inspiration (Sternberg and Lubart, 2005).

A way of considering creativity as a process is through a widely accepted model which was introduced by Wallas and Smith (1926) initially in the form of four stages:

1. Preparation to a problem: focuses the mind of individuals and explores the problem's dimensions,

2. Incubation: the problem is internalized into the unconscious mind; nothing appears to be happening externally,

3. Intimation: the creative person has a "feeling" that a solution is coming,

4. Illumination: eurêka! The creative idea bursts forth from pre-conscious processing into conscious awareness,

This initial model was later completed with a fifth stage:

5. Verification: the idea is verified, elaborated and starts towards an application.

Further developments include Guilford's model which underlined the distinction between convergent and divergent thinking (Guilford, 1967), and Amabile (1996) who suggested that it is important to distinguish a problem-finding or problem-formulation phase, in which relevant information is gathered and preliminary ideas are proposed, from the preparatory phase. Other authors have also considered that more detailed sub-processes are involved in creativity such as perception and information encoding using heuristics as well as the process of forgetting which has been found to play a role in overcoming initial mental fixations. The process of reorganizing information as part of creative thinking has also been considered.

Furthermore, according to Mumford (1991), the phases introduced by Guilford and Amabile occur in a certain kind of approximately organized sequence. In the case of problem formulation they involve the stages of problem construction, search for relevant information, information retrieval and encoding, specification of best fitting categories of information, combination and reorganization of category of information to generate new solutions, idea evaluation, implementation of ideas, and monitoring. According to the same authors, this 
fuzzy organization explains, to a great extent, the variance in the creative performance during problem-solving tasks related to the study domains, these included advertising, managerial and public policy. A model sharing numerous commonalities with the model of Mumford has been proposed by Finke et al. (1992). This model decomposes this loosely organized process into generative and exploratory sub-processes. The generative sub-process includes knowledge retrieval, idea association, synthesis, transformation, and analogical transformation. The exploratory sub-process includes interpretation of re-inventive structures, hypothesis testing, and searching for limitations. These different sub-processes are combined together in the form of iterative cycles leading to creative results. The relationships between the phases and sub-processes of the creative process are complex because they operate almost always simultaneously.

The necessity of analyzing the creative process from different viewpoints and perspectives is also emphasized by Sternberg and Lubart (2005:12). They note that "unidisciplinary approaches have tended to view a part of the phenomenon (e.g., the cognitive processes of creativity, the personality traits of creative persons) as the whole phenomenon; often resulting in what we believe is a narrow, unsatisfying vision of creativity". Considering creativity from a multi-dimensional perspective leads to a better understanding of the creative process and to a more complete picture of its dynamic. In order to push forward this initial state of the art, the further sections focus the design process and later its interdependence with the creative process.

\section{Design as a process:}

Defining design from its results makes little sense as designed artifacts have varied characteristics. They can be produced in varying numbers (from unique large structures to mass produced goods), vary in terms of user perception (be surprising or commonplace), be tangible or intangible (goods vs. software), be produced on varying scales (from nanoparticles to macroscopic level environments), act passively or actively, bring positive or negative additions to life, etc. This list of traits of existing artifacts is, of course, easily expandable but such a list is useless unless one wants to create an exhaustive typology or taxonomy of a set of artifacts. If design cannot be defined purely from its outcome, there is nevertheless a converging vision of design seen as a process (Design Council, 1995; Love, 2002; European commission, 2009).

The starting point of this process is a need (Simon, 1997) that cannot be satisfied immediately by taking resources from nature, by buying or by applying traditional routines (Micaelli and Forest, 2003). In other words, in order to understand what an artifact is, one should first understand its purpose, "what is it made for?" Indeed, a specific feature of designed artifacts is that their essential purpose is to be used and to serve users. The first attribute of an artifact is therefore its function rather than its organic composition or its concrete structure. The adaptation criterion is the adjustment level to a need, defined as an "external constraint". As a consequence, a designer's main assignment does not consist in producing perfect artifacts or artifacts that copy nature as closely as possible; it resides in producing functional artifacts that properly fit particular needs (Coatanéa, 2005). To sum up, a function is seen as a connection made between the "inner environment" of the artifact and its "outer environment" by way of "interfaces" (Simon, 1997). The verification of the functions of the artifact is made by the analysis of its behavior. The artifact has to fulfill an expected behavior.

For designers, this implies the use of deduction in order to select the adequate principles and avoid non-desired effects associated with physical principles. The justification of the design decisions related to artifacts has to be supported by a rational analysis. This rational approach has been developed and explored in the 1980s by the Systematic Design School (Pahl and Beitz, 1984) and in a certain extent by the Value Analysis School (Gage, 1967) in the 1950s 
and 1960s. This exploration has produced guidelines structuring the design process. These guidelines are now largely used in industry. Commonly these guidelines separate the design process into five key phases:

1. Evaluation and selection of ideas: The objective of this first stage is to use the firm's knowledge of its market to identify a promising idea and to insert this new product idea into the firm's "strategic objectives and business sector" (Perrin, 2001:117).

2. Preliminary reflection: This stage aims to understand and clarify the need, in other words, to define the problem and the design environment. This involves setting up a functional analysis process for the new product in order to list the different functions to be fulfilled.

3. Feasibility study (preliminary project study): This stage looks for possible solutions for each of the functions listed as needing to be fulfilled, and evaluates some of the possible combinations.

4. Search for a global solution by assembling solutions to each function: This stage involves some dimensioning of the product.

5. Final design: The objective is the production and verification of a final design.

The design process is an integrative process considering and merging together multiple expectations such as the functionalities, the aesthetic, security, and environmental aspects as well as, from an architectural point of view, multiple components or sub-systems. Due to its complexity and to time and resource constraints, the design activity is seldom a process involving an isolated actor. It relies, on the contrary, most of the time on the cooperation of numerous designers with different expertise and competences. Design is a process where creativity plays a central role; the following section dwells on this aspect.

The creative nature of design: Ingenium

One of the essential properties of design is its creative nature, this aspect has been clearly marked by several authors (Medyna et al., 2009): "Design involves (...) the presence of a creative step" (Archer, 1984); "all designing is iterative, using creativity and compromise to move from a field of possibilities to one unique solution" (Roy, Wield, 1986); "Design is a structured creative process" (UK Department of Trade and Industry, 2005); "Design is a creative activity whose aim is to establish the multi-faceted qualities of objects, processes, services and their systems in whole life cycles" (ICSID, 2009). Considering the creative nature of design leads to the rehabilitation of a kind of reason Western tradition seems to have forgotten (Faucheux, Forest, 2011). It was recognized by Vico through his notion of ingenium and similar to a form of thinking the Greeks called metis.

In De Nostri Temporis Studiorum Ratione (1709), Vico defines ingenium as the ability to understand the relationships that exist between separate elements of reality, therefore establishing relationships between disparate things or concepts. It can be defined as the ability to associate in an effective way scattered items (concepts, things, technologies, knowledge domains...). As such, it is the faculty to bring together different perspectives, to make distinct domains closer, to find and explore relations that none have previously made. Creativity as a whole does not necessarily equate to ingenium. Ingenium is a way of thinking a kind of rationality, involved in design. According to Vico himself ingenium explains how the main Western inventions of the end of the Middle-Ages and the Renaissance (e.g. Brunelleschi's works) were created. Contemporary researchers in innovation (Nonaka, 1994; Maskell, 2001; Antonelli, 2006; Nooteboom et al., 2007) consider knowledge combination, close to the notion of ingemium, as the very origin of innovation.

Contribution of a design centered perspective for understanding creativity from an holistic point of view

If creativity and the notion of ingenium are considered as attributes of the design process, the relationships between creativity, design and innovation need to be clarified in new terms. This 
perspective modifies, for example, the viewpoint proposed by P. Swann and D. Birke (2005). In their interactive model (Fig. 1), creativity and design are linked to innovation as the first contributes to the expansion of available ideas and the second increases the chances of successfully commercializing these ideas. Furthermore, in the same model, creativity directly influences design and appears to be a pre-requisite for it, while design similarly directly influences innovation.

Figure 1: Interactive model of the design process (Swann and Birke, 2005).

Recognizing ingenium as the creative rationality involved in design shows, however, that design can no longer be described as a process linking creativity to innovation channeling ideas for commercial advantage. Creativity becomes a fundamental component of a more global process - the design process - which is itself the central process of the innovation process. This vision is presented in Fig. 2.

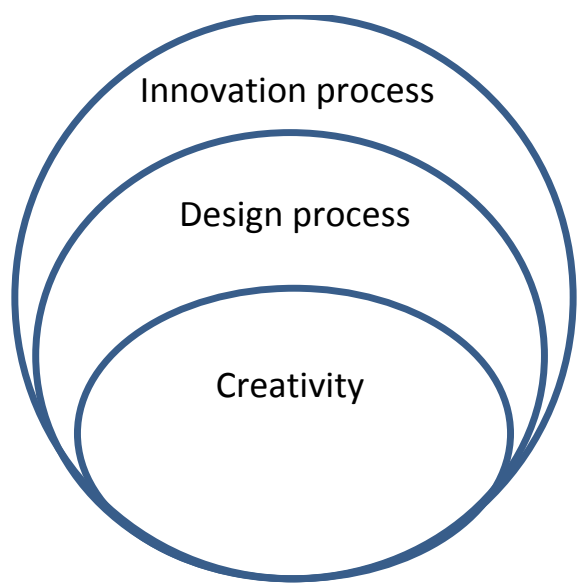

Figure 2: Creativity is part of a more global process.

More precisely, different creative episodes occur during the design process that could be considered as sub-creative processes. The nature of the relationships built during the successive steps of the design process leads to the conclusion that ingenium is a way of thinking which is used during the different phases of the design process creating the link between the firm's knowledge and a market during the first phase of the design process, then establishing links between the future product and its outer physical environment, directly concerning functions. A third type of links is established mainly during the third phase where physical structures have to be imagined for fulfilling functions and steadily linked to those functions by the application of some form of deduction. In a fourth phase, the assembly of components is a form of ingenium. Finally, during the entire design process, and specifically 
during the last phase, problems have to be regularly considered using creative problem solving approaches (Choulier, 2011).

Conclusions and future directions:

The previous analysis highlights the complex links between the notions of design, creativity and innovation. Creativity can no longer be considered as separate from design but rather it must be considered as part of the different sub-processes of design and innovation. The form of creativity involved during design refers to the notion of ingenium, a form of rationality that establishes links between things or concepts.

Such a point of view leads to the conclusion that it is possible to enhance creativity during the design process in order to generate value for individuals, customers, companies or other stakeholders. Another aspect is the innovation that has been analyzed only partially in this short work. It should be developed further in future articles that innovation involves a process of acceptance by the public and the users as well as a historical analysis of the outcome of the creative design process. An innovation is only considered as such if it has gone through the selection of a community of users.

Some other aspects of the links between the three notions of creativity, design and innovation remain open. For example, is it possible to have creativity without design? Some authors seem to defend such a thesis when considering the creative process in artistic domains.

\section{$\underline{\text { References: }}$}

Adam Holbrook A., Hughes L., (2003) Operationalizing definitions of innovation at the level of the firm, Centre for Policy Research on Science and Technology, working paper, Http://www.Utoronto.ca/isrn/documents/holbrook1.Pdf, Accessed on 19.12.2011.

Amabile T. M., andC al., (1996) Assessing the work environment for creativity, Academy of Management Review, Vol.39 (5), 1154-1184.

Antonelli, C. (2006) The Business Governance of Localized Knowledge: An Information Economics Approach for the Economics of Knowledge. Industry and Innovation, 13, $227-61$.

Archer, L., (1984) Systematic method for designers, pp.57-82, in N. Cross (Ed), Development in design methodology, New York : John Wiley \& Sons.

Boden M. (eds), (1996) Dimensions of creativity, MIT Press.

Choulier D., Weite, P.A., (2011), Découvrir et appliquer les outils de TRIZ, Université de

Belfort-Montbéliard, ISBN : 978-914279-55-0.

Coatanéa E., (2005), Conceptual Modeling of Life Cycle Design: A Modeling and Evaluation

Method Based on Analogies and Dimensionless Numbers, PhD dissertation, ISBN 951-22-

7853-7, ISBN 951-22-7852-9.

Design Council, 1995, Definitions of design, London, Design Council.

European Commission, 2009, Design as a driver of user-centred innovation, SEC (2009)501.

Gage, W. L., (1967), Value Analysis, McGraw Hill, London.

Guilford, J.P. (1950). Creativity. American Psychologist, 5, 444-454.

Guilford, J. P. (1967). The Nature of Human Intelligence. McGraw-Hill, New York.

Icsid, 2009, http://www.icsid.org/about/about/articles31.htm, last accessed 05.08.2009. 
Irish Center for Design Innovation. (2007), The design difference. A survey od design and innovation amongst Ireland's SME's

Faucheux M, Forest J., (2011), Stimulating Creative Rationality to Stimulate Innovation Creativity and Innovation Management, Vol 20, Issue 3.

Finke, R. A., and al., (1992). Creative cognition: Theory, research, and applications. Cambridge, MA: MIT Press.

Kline S., Rosenberg N., (1986), An overview of innovation, R. Landau. N. Rosenberg (Eds). The Positive Sum strategy, 275-305, National Academy Press, Washington

Lubart T., (2010), Models of the Creative Process: Past, Present and Future, Creativity Research Journal, 13:3-4, 295-308.

Love T., (2002), Constructing a coherent cross-disciplinary body of theory about designing and designs: some philosophical issues, Design Studies, Volume 23, Issue 3, May 2002, 345-361.

MacKinnon D.W., (1978), In search of human effectiveness: Identifying and developing creativity, Creative Education Foundation, New York.

Maskell, P. (2001), " Knowledge creation and diffusion in geographic clusters », International journal of innovation Management, vol 5, n², 213-237.

Medyna G., Coatanéa E., Lahti L., Howard T., Brace W., Christophe F., (2009) Creative design: An initial analysis and ontology, submitted to MCPC 2009 (Mass Customization and Personalization Conference 2009), Helsinki, Finland.

Micaelli, J.P., Forest J., 2003, Artificialisme, Lausanne, Presses Polytechniques Universitaires Romandes.

Mumford, M. D., Mobley, M. I., Uhlman, C. E., Reiter-Palmon, R.,\& Doares, L. M. (1991). Process analytic models of creative capacities. Creativity Research Journal, 4, 91-122.

Nonaka, I. (1994), « A dynamic theory of organizational knowledge creation », Organization Science, $5, \mathrm{n}^{\circ} 1,14-37$.

Nooteboom, B. et al. (2007), « Optimal cognitive distance and absorptive capacity », Research Policy, Volume 36, Issue 7, september 2007, 1016-1034.

Oslo Manual (2005), The measurement of scientific and technological activities,

http://www.oecd.org/dataoecd/35/61/2367580.pdf

Pahl G., Beitz W., (1984) Engineering design: a systematic approach, London: Springer.

Perrin J., 2001, Concevoir l'innovation industrielle. Méthodologie de conception de l'innovation, Paris, CNRS Editions.

Roy, R., Wield, D. (1986) Product Design and Technological Innovation. Open University Press, Milton Keynes, Philadelphia, PA.

Simon H.A., 1997. The Sciences of the Artificial. MIT Press, Cambridge, third edition.

Sternberg, R.J., Lubart, T.I., (2005), The Concept of Creativity: Prospects and Paradigms, pp. 3-14, R.J. Sternberg, Handbook of Creativity, Cambridge : Cambridge University Press.

Swann, P., Birke, D., (2005), How do creativity enhance business performance ? A framework for interpreting the evidence, Think piece for DTI Strategy Unit, Final report, Nottingham University Business School. 
Swedish Industrial Design Foundation (2008)

Tether, B., 2009, Design in Innovation Coming out from the Shadow of R\&D An Analysis of the UK Innovation Survey of 2005, Department for Innovation, Universities and Skills Research Report 09-12, London.

Uk Department of Trade and Industry, (2005), Creativity, design and business performance, Economics Paper, 15.

Vico G., (1709), De Nostri Temporis Studiorum Ratione.

Wallas G., Smith R., (1926), Art of Thought, New York: Harcourt Brace. 